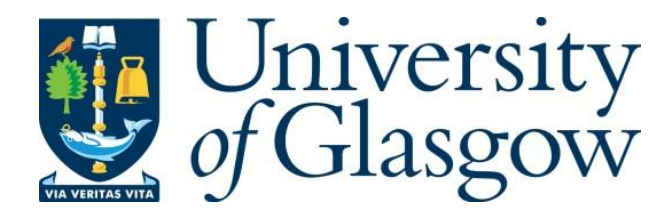

Wang, J., Al-Khalidi, A., Alharbi, K., Ofiare, A., Zhou, H., Wasige, E., and Figueiredo, J. (2017) High Performance Resonant Tunneling Diode Oscillators as Terahertz Sources. In: European Microwave Conference, London, 3-7 Oct 2016, pp. 341-344. ISBN 9782874870439.

There may be differences between this version and the published version. You are advised to consult the publisher's version if you wish to cite from it.

http://eprints.gla.ac.uk/123126/

Deposited on: 22 August 2016

Enlighten - Research publications by members of the University of Glasgow http://eprints.gla.ac.uk 


\section{High Performance Resonant Tunneling Diode Oscillators as Terahertz Sources}

\author{
Jue Wang, Abdullah Al-Khalidi, Khalid Alharbi, \\ Afesomeh Ofiare, Haiping Zhou, and Edward Wasige \\ High Frequency Electronics Group, School of Engineering \\ University of Glasgow, Glasgow, United Kingdom \\ Jue.Wang@glasgow.ac.uk
}

\begin{abstract}
This paper presents a series of monolithic microwave integrated circuit (MMIC) resonant tunneling diode (RTD) oscillators. The oscillator circuit topology employs two InGaAs/AIAs RTDs in parallel and each device is biased individually. The oscillators operate at $125 / 156 / 206 / 308 \mathrm{GHz}$ with $-1.7 /-3.3 /-14.6 /-4.8 \mathrm{dBm}$ output power. With improved epitaxial layer structures and oscillator designs, it is expected that the output power will reach several milliwatts. This work shows the promising potential of RTD oscillators as terahertz (THz) sources for high speed wireless communications, etc.
\end{abstract}

Keywords-monolithic microwave integrated circuit (MMIC), resonant tunneling diode (RTD), millimetrewave, oscillators

\section{INTRODUCTION}

As the demand for high speed wireless communication increases, compact and room temperature operation terahertz $(\mathrm{THz})$ transmitters and highly sensitive detectors are required. The resonant tunneling diode (RTD) is one of the most promising technology platforms for electronic $\mathrm{THz}$ communications, see e.g. [1]-[3]. It is, to date, the fastest semiconductor-based electronic device with the highest reported frequency at $1.55 \mathrm{THz}$ [3]. Recently, a data transmission rate of $3 \mathrm{Gbps}$ at $540 \mathrm{GHz}$ by using RTD oscillator was demonstrated even though the distance coverage was only a few centimeters due to the low oscillator output power [4]. Presently, nonoptimal epitaxial device designs as well as inefficient circuit designs result in the reported low oscillator output powers, and these are the main challenges to the development of RTD technology. For the next generation multi-gigabit wireless communications front-ends, practically relevant output powers of at least $10 \mathrm{~mW}$ at $90 \mathrm{GHz}, 5 \mathrm{~mW}$ at $160 \mathrm{GHz}$ and $1 \mathrm{~mW}$ at $300 \mathrm{GHz}$ are required [5], for example, for the future wireless indoor communications in femtocell scenarios [6]. These are yet to be demonstrated as single compact electronic sources in integrated circuit form but RTDs are strong contenders [7].

Common RTD oscillator design approaches have targeted the highest possible frequencies, up to $1 \mathrm{THz}$ and beyond, and so have necessarily required integrated antenna loads, see e.g. [1-4]. For these predominantly indium phosphide (InP) based RTDs, the influence of the substrate to the antenna radiation pattern because of its high permittivity, see e.g. [8], makes the accurate characterization of the oscillator power less than robust, and thereby limiting feedback information for technology optimization. In this paper, monolithically integrated circuit

\author{
José Figueiredo \\ Departamento de Física da Faculdade de Ciências e \\ Tecnologia, \\ Universidade do Algarve, Campus de Gambelas, Faro. \\ jlongras@ualg.pt
}

RTD oscillators in coplanar waveguide (CPW) technology fabricated using photolithography and which operate in $100-$ $310 \mathrm{GHz}$ range with relatively high output power are reported. They are realized in a power combining circuit topology and designed for accurate on-wafer characterization in conventional $50-\Omega$ measurement systems. The designs target frequencies in the $\mathrm{W}$-band to $\mathrm{H}$-band for the aforementioned future wireless front-ends and can be used in their present form with external horn antennas for laboratory experiments.

\section{RTD EPI-LAYER DESIGN}

InP-based RTD devices consist of a low bandgap quantumwell (InGaAs with bandgap $\mathrm{E}_{\mathrm{g}}=0.71 \mathrm{eV}$ ) sandwiched between two high bandgap barriers (AlAs with $\mathrm{E}_{\mathrm{g}}=2.16 \mathrm{eV}$ ), forming the so-called double barrier quantum-well structure [9]. In this paper, some insight to the epitaxial layer designs and their impact on oscillator performance is provided through a comparison of two nominally identical designs. The epitaxial material I and II, shown in Table 1, was grown by molecular beam epitaxy (MBE) on a semi-insulating InP substrate. For both structures, the lattice-matched InGaAs quantum-well and AlAs barrier thickness were kept as constant as $4.5 \mathrm{~nm}$ and $1.4 \mathrm{~nm}$, respectively. The main difference in the epitaxial structures was the thickness of the the spacer layers which was $50 \mathrm{~nm}$ for epilayer I and $25 \mathrm{~nm}$ for epilayer II.

RTD devices were sized as described in Ref. [10]. For these epitaxial structures, the devices are micron-sized and so were fabricated using optical lithography. The device mesa was defined by wet etching $\mathrm{H}_{3} \mathrm{PO}_{4}: \mathrm{H}_{2} \mathrm{O}_{2}: \mathrm{H}_{2} \mathrm{O}$ and passivated by polyimide $\mathrm{PI}-2545$, which has a low dielectric constant. More fabrication details can be found in [11]. The DC measurement results of RTD device with the same device size $\left(16 \mu \mathrm{m}^{2}\right)$ are plotted in Fig. 1 and compared in Table 2, where $V_{p} / I_{p}$ is the peak voltage/current, $\mathrm{V}_{\mathrm{v}} / \mathrm{I}_{\mathrm{v}}$ is the valley voltage/current, PVCR is the peak to valley current ratio, $C_{n}$ * is the nominal geometrical self-capacitance which is estimated by $C_{n} *=\varepsilon_{0} \varepsilon_{r} / d$, where $\varepsilon_{r}$ is the dielectric constant of InGaAs, $\varepsilon_{0}$ is the permittivity of free space and $d$ is the total thickness of the spacer, quantum well and barrier layers. The maximum available power $\left(\mathrm{P}_{\max }\right)$ of single RTD oscillator can be estimated from $\frac{3}{16} \Delta \mathrm{V} \Delta \mathrm{I}$ [12], where $\Delta \mathrm{V}$ and $\Delta \mathrm{I}$ are the peak-to-valley voltage and current differences respectively. 
For epi-layer I, the peak current density is about $63 \mathrm{kA} / \mathrm{cm}^{2}$, PVCR is 1.8 , and $C_{n}{ }^{*}$ is $2.0 \mathrm{fF} / \mu \mathrm{m}^{2}$ compared to epi-layer II with peak current density $215 \mathrm{kA} / \mathrm{cm}^{2}$, PVCR of 3.3 and $C_{n} *$ of 3.6 $\mathrm{fF} / \mu^{2}$. The high peak current density is due to improved fabrication processing and low contact resistances, and also due to the reduced bulk series resistance of the thinner spacer layer which also makes the device have a lower peak voltage [13]. The estimated power for layer II device is over 4 times higher than layer I. However, the larger negative differential conductance for layer II requires a low resistance for bias stabilisation which compromises/reduces the DC-RF circuit efficiency.

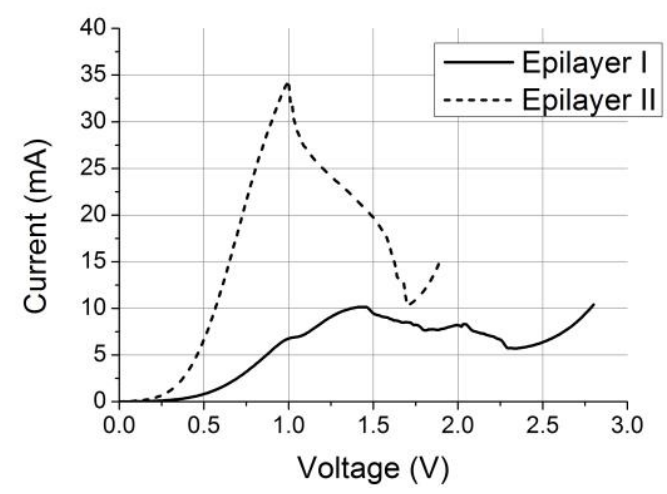

Fig. 1. I-V measurement comparison between epi-layer I and II.

TABLE 1. EPI-LAYER I AND II

\begin{tabular}{|c|c|c|c|c|}
\hline \multicolumn{2}{|c|}{$\begin{array}{c}\text { Thickness } \\
\text { (̊) }\end{array}$} & \multirow[t]{2}{*}{ Composition } & \multirow[t]{2}{*}{$\begin{array}{l}\text { Doping } \\
\text { (cm-3) }\end{array}$} & \multirow[t]{2}{*}{ Description } \\
\hline $\mathbf{I}$ & II & & & \\
\hline 400 & 400 & $\mathrm{In}_{0.53} \mathrm{Ga}_{0.47} \mathrm{As}$ & 3E19: Si & Emitter \\
\hline 800 & 1600 & $\mathrm{In}_{0.53} \mathrm{Ga}_{0.47} \mathrm{As}$ & $2 \mathrm{E} 18: \mathrm{Si}$ & Emitter \\
\hline 500 & 250 & $\mathrm{In}_{0.53} \mathrm{Ga}_{0.47} \mathrm{As}$ & $2 \mathrm{E} 16: \mathrm{Si}$ & Spacer \\
\hline 14 & 14 & AlAs & Un-doped & Barrier \\
\hline 45 & 45 & $\mathrm{In}_{0.53} \mathrm{Ga}_{0.47} \mathrm{As}$ & Un-doped & Well \\
\hline 14 & 14 & AlAs & Un-doped & Barrier \\
\hline 500 & 250 & $\mathrm{In}_{0.53} \mathrm{Ga}_{0.47} \mathrm{As}$ & $2 \mathrm{E} 16: \mathrm{Si}$ & Spacer \\
\hline 800 & 250 & $\mathrm{In}_{0.53} \mathrm{Ga}_{0.47} \mathrm{As}$ & 2E18: $\mathrm{Si}$ & Collector \\
\hline 100 & 100 & $\mathrm{In}_{0.52} \mathrm{Al}_{0.48} \mathrm{As}$ & 1E19:Si & Etch stop \\
\hline 2000 & 2000 & $\mathrm{In}_{0.53} \mathrm{Ga}_{0.47} \mathrm{As}$ & 3E19: Si & Collector \\
\hline 2000 & 2000 & $\mathrm{In}_{0.53} \mathrm{Ga}_{0.47} \mathrm{As}$ & $2 \mathrm{E} 19: \mathrm{Si}$ & Buffer \\
\hline \multicolumn{4}{|c|}{ SI : InP } & Substrate \\
\hline
\end{tabular}

TABle 2. DC MEASUREMENT RESUlTS

\begin{tabular}{|c|c|c|c|c|c|}
\hline $\begin{array}{c}\text { Epi- } \\
\text { layer }\end{array}$ & $\begin{array}{c}\mathbf{V}_{\mathbf{p}} / \mathbf{I}_{\mathbf{p}} \\
(\mathbf{V} / \mathbf{m A})\end{array}$ & $\begin{array}{c}\mathbf{V}_{\mathbf{v}} / \mathbf{I}_{\mathbf{v}} \\
(\mathbf{V} / \mathbf{m A})\end{array}$ & $\mathbf{P V C R}$ & $\begin{array}{c}\boldsymbol{C}_{\boldsymbol{n}}{ }^{*} \\
\left(\mathbf{f F} / \mathbf{\mu m}^{\mathbf{2}}\right)\end{array}$ & $\begin{array}{c}\mathbf{P}_{\max } \\
(\mathbf{m W})\end{array}$ \\
\hline I & $1.5 / 10.1$ & $2.3 / 5.7$ & 1.8 & 2.1 & 0.66 \\
\hline II & $1.0 / 34.4$ & $1.7 / 10.4$ & 3.3 & 3.6 & 3.15 \\
\hline
\end{tabular}

\section{RTD OSCILLATOR DESIGN}

The RTD oscillator design approach presented here employs two RTDs in parallel as shown in Fig. 2(a). Each device is biased individually with its own shunt resistor $R_{e}$ to suppress the low frequency bias oscillations and a bypass capacitor $C_{e}$ to shortcircuit the RF signal to ground. Inductance $\mathrm{L}$ is designed to resonate with RTD self-capacitances to obtain the desired frequency. It is realized from an appropriate length of a coplanar waveguide (CPW) terminated in a short circuit, through capacitor $C_{e}$ in this case. $R_{L}$ is the load resistance which is 50-
$\Omega$, the input impedance of the spectrum analyser or power meter used in the characterization setup. The RF equivalent circuit of the oscillator circuit is shown in Fig. 2(b). $G_{n}$ and $C_{n}$ are the device differential conductance and self-capacitance in the negative differential resistance region, respectively. The circuit was realized in MMIC form. The shunt resistor $R_{e}$ was fabricated using thin film $\mathrm{NiCr}(33 \mathrm{~nm})$. The value was chosen to suppress the bias oscillation [10] and the bypass capacitor $\mathrm{C}_{\mathrm{e}}$ was realized as metal-insulator-metal (MIM) capacitor. Thin dielectric layer $\mathrm{Si}_{3} \mathrm{~N}_{4}(75 \mathrm{~nm})$ was deposited by inductively coupled plasma (ICP) chemical vapor deposition (CVD). The inductance $\mathrm{L}$ was introduced by a shorted CPW line with a chosen/suitable characteristic impedance. From transmission line theory, it is known when the transmission line electrical length is less than $90^{\circ}$, the structure act as an inductor $L$, the value can be estimated by

$$
L=\frac{Z_{0} \tan (\beta l)}{2 \pi f_{0}}
$$

where $Z_{0}$ is the $\mathrm{CPW}$ characteristic impedance, $\beta$ is the phase constant, $l$ is the physical length of the $\mathrm{CPW}, f_{0}$ is the designed frequency. A photograph of the fabricated oscillator with probes landing on top of CPW structure is shown in Fig. 3.

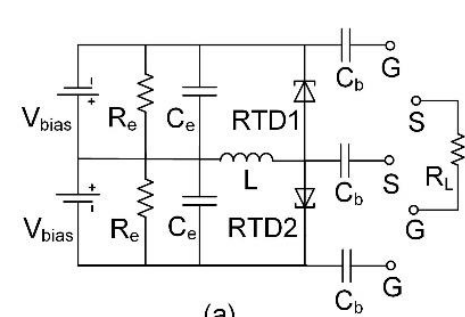

(a)

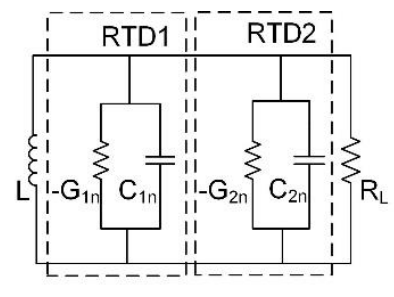

(b)
Fig. 2. (a) Two RTD oscillator schematic circuit. Each RTD is biased individually with its own DC stabilization circuit $R_{e}$ and $C_{e}$. (b) Oscillator $R F$ equivalent circuit excluding device parasitic elements.

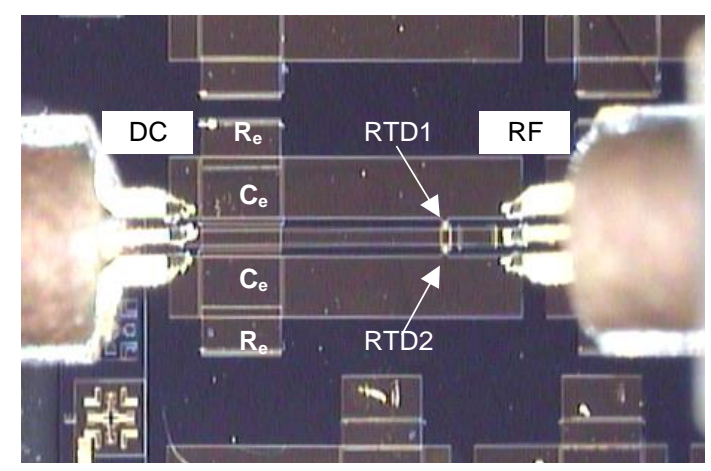

Fig. 3. Photograph of the fabricated oscillator that employs 2 RTD devices during measurement setup with probes landed on the chip.

\section{MEASUREMENT RESUlTS}

The RTD oscillators were characterized on-wafer by using a $50 \mathrm{GHz}$ Agilent E4448A spectrum analyzer with an appropriate external mixer for oscillation frequencies in the $\mathrm{D} / \mathrm{G} / \mathrm{H}$-bands. The schematic diagram of the measurement setup is shown in Fig. 4(a). The DC bias were applied from left side, while a GSG Picoprobe was used to extract their RF outputs. The measured signal was mixed down by using D-band/G-band/H-band 
harmonic mixer from Farran Technology. A $2.5 \mathrm{~mm}$ coax cable was used to connect the mixer and diplexer. The diplexer is used to separate the local oscillator (LO) and intermediate frequencies (IF). The output power was first noted from the spectrum analyser by considering the typical conversion loss of the mixer as specified in the datasheet, then the oscillator output was measured directly using a power meter, the Erikson PM4. The measurement setup is as shown in Fig. 4(b). The reported output powers were corrected for the $3 \mathrm{~dB}$ insertion loss that is specified by the manufacturer for the power meter setup.

There were three different device sizes, $3 \times 5 \mu \mathrm{m}^{2}, 4 \times 4 \mu \mathrm{m}^{2}$ and $5 \times 5 \mu^{2}$ employed in the oscillator circuits, together with three different CPW lengths, $5 \mu \mathrm{m}, 10 \mu \mathrm{m}$ and $30 \mu \mathrm{m}$, aiming at different frequencies. By using epilayer II, the measured highest spectra of $307.6 \mathrm{GHz}$ is shown in Fig. 5 when bias voltage $\mathrm{V}_{\text {bias }}=1.65 \mathrm{~V}$ and total current $\mathrm{I}_{\text {bias }}=116 \mathrm{~mA}$. The results are summarized in Table 3 together with the oscillator results $(125 / 156 / 206 \mathrm{GHz})$ by using epilayer I for comparison. The 125 GHz oscillator employing two $5 \times 5 \mu \mathrm{m}^{2}$ devices and $30 \mu \mathrm{m}$ long CPW provided $0.68 \mathrm{~mW}(-1.7 \mathrm{dBm})$ output power while the 156 $\mathrm{GHz}$ oscillator employing two smaller $3 \times 5 \mu \mathrm{m}^{2}$ devices but also a $30 \mu \mathrm{m}$ long CPW provided $0.47 \mathrm{~mW}(-3.3 \mathrm{dBm})$ output power; and $206 \mathrm{GHz}$ oscillator with $35 \mu \mathrm{W}(-14.6 \mathrm{dBm})$ power employed two $4 \times 4 \mu^{2}$ with a $5 \mu \mathrm{m}$ long CPW. Note that the $308 \mathrm{GHz}$ oscillator used a $25-\Omega \mathrm{CPW}$ line while the other oscillators used $50-\Omega$ lines.

The single side band (SSB) phase noise $\left(\mathcal{L}\left(\mathrm{f}_{\mathrm{m}}\right)\right)$ of RTD oscillator can be characterized by using direct spectrum analysis [14]

$$
\mathcal{L}\left(\mathrm{f}_{\mathrm{m}}\right)=\mathrm{P}_{\mathrm{m}}-\mathrm{SF}_{\mathrm{bw}}+\mathrm{C}_{\mathrm{m}}-\mathrm{P}_{\mathrm{s}}
$$

where $\mathrm{P}_{\mathrm{m}}$ is the measured noise level, $\mathrm{SF}_{\mathrm{bw}}$ is noise bandwidth normalization, $\mathrm{C}_{\mathrm{m}}$ is correction for the measurement system, and $\mathrm{P}_{\mathrm{s}}$ is the carrier level. The calculated $\mathcal{L}\left(\mathrm{f}_{\mathrm{m}}\right)$ at $1 \mathrm{MHz}$ offset for the $308 \mathrm{GHz}$ oscillator was about $-81 \mathrm{dBc} / \mathrm{Hz}$.

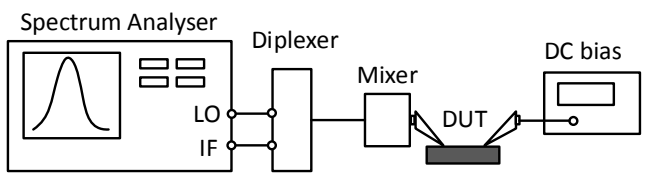

(a)

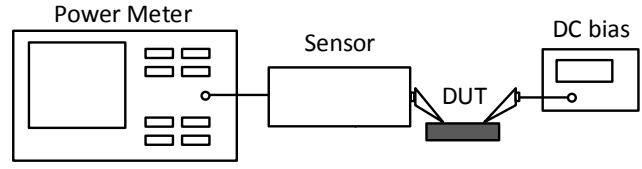

(b)

Fig. 4. Schematic diagram (a) on-wafer spectrum measurement. (b) Power measurement setup.

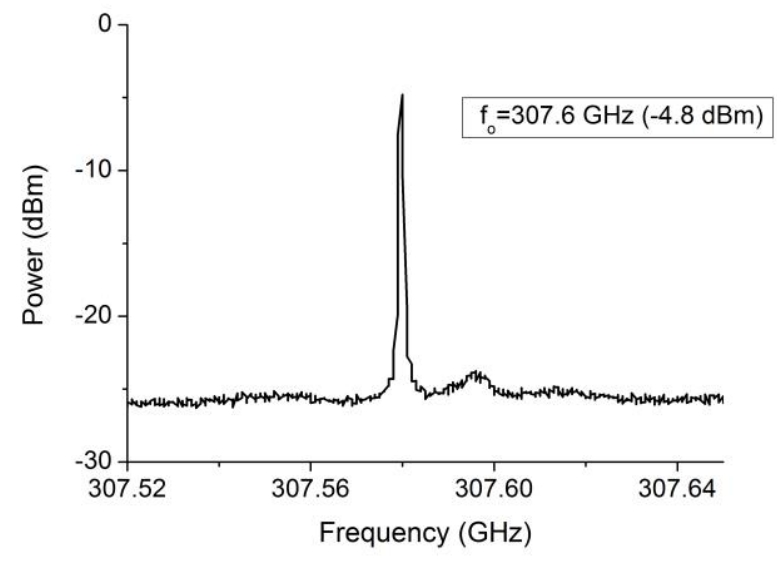

Fig. 5. Measured spectrum of the $307.8 \mathrm{GHz}$ oscillator when $\mathrm{V}_{\text {bias }}=1.65 \mathrm{~V}$, $\mathrm{I}_{\text {bias }}=116 \mathrm{~mA}$

TABLE 3 SUMMARY OF RTD OSCILLATORS PERFOMANCE

\begin{tabular}{|c|c|c|c|c|c|}
\hline $\begin{array}{c}\text { Epi- } \\
\text { layer }\end{array}$ & $\begin{array}{c}\text { Device } \\
\text { size } \\
\left(\boldsymbol{\mu \mathbf { m } ^ { 2 } )}\right.\end{array}$ & $\begin{array}{c}\text { CPW } \boldsymbol{Z}_{\boldsymbol{o}}(\mathbf{\Omega}) / \\
\text { length }(\boldsymbol{\mu m})\end{array}$ & $\begin{array}{c}\text { Freq. } \\
(\mathbf{G H z})\end{array}$ & $\begin{array}{c}\text { Power } \\
(\mathbf{d B m} / \mathbf{m W})\end{array}$ & $\begin{array}{c}\text { DC } \\
\text { Power } \\
(\mathbf{m W})\end{array}$ \\
\hline I & $5 \times 5$ & $50 / 30$ & 125 & $-1.7 / 0.68$ & 415 \\
\hline I & $3 \times 5$ & $50 / 30$ & 156 & $-3.3 / 0.47$ & 374 \\
\hline I & $4 \times 4$ & $50 / 5$ & 206 & $-14.6 / 0.035$ & 108 \\
\hline II & $4 \times 4$ & $25 / 10$ & 308 & $-4.8 / 0.33$ & 191 \\
\hline
\end{tabular}

\section{DISCUSSION AND CONCLUSION}

High frequency and high power free-running resonant tunneling diode oscillators realised with a simple photolithography fabrication process have been described in this paper. The micron-sized but still very broadband RTD devices make this possible. This is a key advantage of RTD oscillators compared to transistor based oscillators where for this frequency range, very fine sub-micron or even sub-100nm features are required. The adopted design approach which allows on-wafer characterization enables a more accurate characterization of the oscillator output power and this will impact on future designs. The presented RTD oscillator designs can be used in their present form with commercially available external high gain horn antennas for laboratory experiments exploring new applications possible at the high frequencies.

Future work is aimed at further improving the oscillator output power levels to the levels desired by industry, integrating the oscillators with suitable antennas, and reducing oscillator phase noise.

\section{ACKNOWLEDGMENT}

The authors thank the staff of the James Watt Nanofabrication Centre (JWNC) at the University of Glasgow for help in fabricating the devices. This work was supported by the Engineering and Physical Sciences Research Council (EPSRC), grant number EP/J019747/1 and in part by the European Commission, grant agreement no. 645369 (iBROW project).

\section{REFERENCES}


[1] M. Asada, S. Suzuki, and N. Kishimoto, "Resonant tunnelling diodes for subterahertz and terahertz oscillators," Japanese Journal of Applied Physics, vol. 47, No. 6, pp. 4375-4384, 2008.

[2] M. Feiginov, C. Sydlo, O. Cojocari, and P. Meissner, "Resonanttunnelling-diode oscillators operating at frequencies above $1.1 \mathrm{THz}$ ", Applied Physics Letters, No. 99, 2011.

[3] T. Maekawa, H. Kanaya, S. Suzuki, and M. Asada, " Frequency increase in terahertz oscillation of resonant tunnelling diode up to $1.55 \mathrm{THz}$ by reduced slot-antenna length," Electronics Letters, vol.50, no.17, pp.12141216,2014

[4] M.Asada, S.Suzuki, "Compact $\mathrm{THz}$ oscillators with resonant tunneling diodes and application to high-capacity wireless communications," $21 \mathrm{st}$ International Conference on Applied Electromagnetics and Communications (ICECom), pp.1-5, 2013.

[5] W. Templ and A. Pascht, "Perspectives for commercialisation of RTDs in high performance mmWave transceivers," Workshop on Compact and High-Performance Millimetre-wave and Terahertz Sources/Systems, European Microwave Week, London, UK, 2016.

[6] R. Hoppe, D. M. Rose, R. Wahl, G. Wölfle and T. Kürner, "Simulator for the analysis of the mutual impact between indoor femtocells and urban macrocells," 6th European Conference on Antennas and Propagation (EuCAP 2012), Prague, Czech Republic, 2012.

[7] www.ibrow-project.eu (accessed $27^{\text {th }}$ May 2016)
[8] K.H. Alharbi, Ata Khalid, A. Ofiare, J. Wang and E. Wasige, "Broadband Bow-Tie Slot Antenna with Tuning Stub for Resonant Tunnelling Diode Oscillators with Novel Configuration for Substrate Effects Suppression," European Microwave Conference, London, UK, 2016.

[9] H. Mizuta and T. Tanoue, "The Physics and Applications of Resonant Tunnelling Diodes," Cambridge University Press, 2006.

[10] J. Wang, L. Wang, C. Li, B. Romeira, and E. Wasige, "28 GHz MMIC Resonant Tunneling Diode Oscillator of around $1 \mathrm{~mW}$ Output Power," Electronics letters, vol. 49, No.13, pp. 816-818. 2013

[11] J. Wang, L. Wang, C. Li, K. Alharbi, A. Khalid and E. Wasige, "W-band InP-based Resonant Tunnelling Diode Oscillator with Milliwatt Output Power," The 26th International Conference on Indium Phosphide and Related Materials, Montpellier, France, 2014.

[12] C. S. Kim and A Brandli, "High-Frequency High-Power Operation of Tunnel Diodes," IRE Transactions on Circuit Theory, 1961, pp.416-525

[13] V.P.Kesan, A. Mortazawi, D.R. Miller, V.K. Reddy, Neikirk, P. Dean, T. Itoh, "Microwave and millimeter-wave QWITT diode oscillators," IEEE Transactions on Microwave Theory and Techniques, vol.37, no.12, pp.1933-1941, 1989.

[14] K. Feher and Engineers of Hewlett-Packard, "Telecommunications Measurements, Analysis, and Instrumentation," SciTech Publishing, 1997. 